\title{
A Unit for Applying Liquid Fertilizers
}

\author{
Sergey Belousov ${ }^{1,2, *}$ and Yury Khanin $^{1}$ \\ ${ }^{1}$ Kuban State Agrarian University named after I.T.Trubilin, Krasnodar, Russian Federation \\ ${ }^{2}$ Agrarian Scientific Center "Donskoy, department of "North-Caucasus scientific-research institute of \\ agricultural mechanization and electrification", Zernograd, Russia
}

\begin{abstract}
The work is devoted to methods and means for applying concentrated fertilizers. The article has an analytical character, which is expressed in the fact that the methods and means of mechanization for applying liquid fertilizers are given, as well as excerpts from the works of scientists on the subject under study. The main trend in the development of means for the use of liquid fertilizers is determined, the issues of improving the quality indicators of their work are considered. The technology of using liquid fertilizers and the development of mechanization tools for their application is also justified. The main results achieved so far and the prospects for the development of this direction are presented.
\end{abstract}

One of the important aspects of cultivation of agricultural crops in the general system of agriculture is the introduction of fertilizers. Currently, fertilizers are an integral part of agriculture. The quality of products, their maturation, and yield depend on their application. A special place in this issue is occupied by the introduction of liquid fertilizers.

The work is carried out within the framework of creative and scientific cooperation with TeeJet Technologies, Krasnodar "https://www.teejet.com/ru/index.aspx". The work is of an analytical nature, it is carried out on the basis of the analysis of expert assessments of scientists.

The use of plant protection products of the PPM (plant protection means) leads in general to an increase in the content of all the essential and necessary nutrients for plants in the soil, but with regular cultivation of agricultural crops, their reserve is depleted, and then we have to make additional fertilizers in the liquid form.

Currently, fertilizers are applied by mounted, semi-mounted trailed machines. The same applies to the method of their aggregation [1].

For a more holistic perception and further implementation of the idea of developing a design for applying fertilizers, it is necessary to make a patent search of promising developments, machines. To do this, we use publicly available search tools on the Internet sites http://www1.fips.ru and http://www.findpatent.ru / these resources allow us to make a holistic review of patent designs of mechanization tools in the field of agricultural engineering.

As a result of the analysis of patents in the field of tools of mechanization of liquid fertilizers, we have identified a general trend in the development of this problem, and also iden-

\footnotetext{
*Corresponding author: sergey_belousov_87@mail.ru
} 
tified the designs of the most promising tools that can be industrially applicable, however, have a number of technical and technological disadvantages $[2,3]$.

Thus, we have established that the device for chemical treatment of plants, RU 2400066 C1., which contains tunnel shelters over rows of plants, equipped with height-adjustable shields, trapping tanks with funnels, a pipeline and a pump for discharging the spent liquid into the tank. Nozzles for supplying liquid preparations to the interior of tunnel shelters are located along their contour in the middle part with the possibility of adjusting their position and quantity depending on the size of the crown of plantings.

It is known that the device according to the patent RU $2386250 \mathrm{C} 2$ on a rod sprayer, which refers to machines for protecting agricultural plants from pests. The rod sprayer has a hydraulic system with a drive and a rod installed on the motor unit. Spring-loaded doublearm levers are pivotally mounted on the rod, a working fluid sprayer is installed on the lower shoulder of each of them, and a sailing element is installed on the upper one.

We also found that patents and utility models RU 155061 U1, RU 194515 U1, RU $2386250 \mathrm{C} 2$, cannot produce an accurate dosed uniform spread of the material over the entire width of the grip.

Also known is the sprayer patent RU 85800 U1 for applying liquid concentrated fertilizers, which contains a frame with two drive wheels and one support wheel on a rack connected to the rear hitch, an engine with a starter, a fuel tank and an air filter, a gearbox with a gear lever, a V-belt transmission, an electric generator, a battery, steering in the form of handles, a front hitch, including horizontal and vertical frames with guides, a tank for working fluids, a composite rod with sprayers, windproof casing.

The disadvantage of this technical solution is the imperfection of the device, namely, the lack of the ability to make a dosed and uniform application of the working solution over the entire width of the grip in a limited space of its use, and the technical result is to ensure the possibility of applying liquid concentrated fertilizers in conditions of limited land use.

Based on the identified technical solutions, we propose a design (Figure 1) for applying liquid fertilizers, which contains a modular system for the layout of working executive bodies and controls. The technical result is achieved by the fact that in a structure for applying liquid concentrated fertilizers, containing a frame with two drive wheels and one support wheel on a rack connected to the rear hitch, an engine with a starter, a fuel tank and an air filter, a gearbox with a gear lever, a V-belt transmission, an electric generator, a battery, steering in the form of handles, a front hitch, including horizontal and vertical frames with guides, a tank for working fluids, a composite rod with sprayers, a windproof casing. According to the proposed technical solution, there is an additional support wheel connected to the front hitch, on which a tank for working fluid is installed in a sealed manner, a windproof casing is located between the drive wheels and the front support wheel, a counterweight is located on the rear rack, while the composite rod with sprayers has pressure equalization valves inside the rod inserted into the ends of the rod, and a control panel is located on the steering handle, communicating with the tank for working fluid $[3,4]$.

This technical solution is due to the fact that due to the design features of the sprayer, an increase in the productivity of liquid fertilizers is provided in conditions of limited land use, which will significantly improve the quality of the products obtained and increase the productivity of this technological operation. The technical solution is industrially applicable and can be manufactured in the factory $[5,6,7]$. 

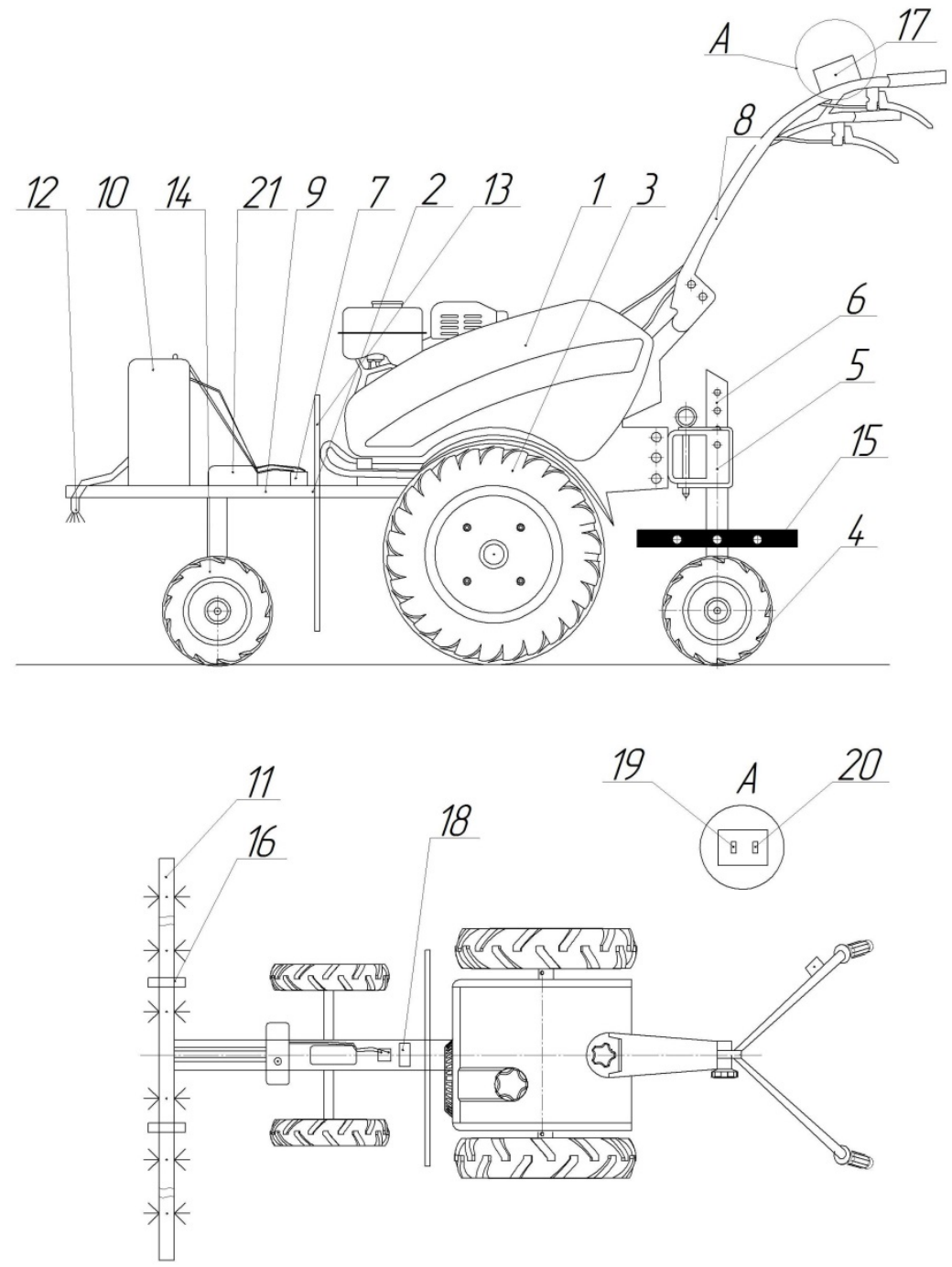

Fig. 1. Proposed technical solution

The structure for applying liquid concentrated fertilizers contains a tool for moving 1 , made in a motor cultivator, a frame 2 with two water wheels 3 and one support wheel 4 on a rack 5 connected to the rear hitch 6 , an engine with a starter, a fuel tank and an air filter, a reducer with a gear lever, a V-belt transmission, an electric generator, an accumulator 7 , steering in the form of handles 8 , a front hitch 9, including horizontal and vertical frames with guides, sealed tank 10 for working fluid, composite rod 11 with sprayers 12 , windproof cover 13. The sprayer has additional support wheels 14 connected to the front hitch 9 , on which a sealed tank 10 for working fluids is installed, a wind-protective casing is located between the drive wheels 3 and the front support wheels 14, an imbalance 15 is located on the rack 5 of the rear support wheel 4, while the rod 11 with sprayers 13 is telescopic and has compensation valves 16 for equalizing the pressure inside the rod inserted into the ends of the rod, a control panel 17 is located on the steering handle 8, communicated through pipelines with a working fluid tank. 
The design works as follows: during the movement of the sprayer for applying liquid concentrated fertilizers, after the operator presses the first key on the control panel 17, the compressor turns on, which creates pressure in the receiver 18 , and then in the tank with the working fluid 10, after pressing the second key, a valve opens, through which liquid concentrated fertilizers under pressure through a pipeline from a sealed tank 10, enter the composite rod 11, where then through the sprayers 12 they get to the plants, the imbalance 15 makes it possible to smoothly adjust the balance of the unit depending on the change in the level of the working fluid in the tank 10, the tank 10, in turn, has a relief valve for venting excess pressure in the system $[8,9,10]$.

The result of the work carried out is that the design for applying liquid fertilizers has a smaller size, a differentially adjustable gripping width, which is more precisely adapted to work in conditions of limited land use. This technical solution is patented on the territory of the Russian Federation and is undergoing laboratory and field researches at Kuban State Agrarian University.

\section{References}

1. S.V. Belousov, D.A. Filippov, Collection: E3S Web of Conferences. Ser. "International Conference on Modern Trends in Manufacturing Technologies and Equipment, ICMTMTE 2020", Introduction of fertilizers to the field surface, p. 01011, (2020).

2. S.I. Kambulov, V.I. Vyalkov, A.Ya. Ksenz, In the collection: State and prospects for the development of agricultural engineering. materials of the 5th international scientific and practical -conference in the framework of the 15th International agroindustrial exhibition "Interagromash-2012". Ministry of Agriculture of the Russian Federation, Russian Academy of Agricultural Sciences (RAAS), Determination of the optimal doses of liquid complex fertilizers, S. 110-113, (2012).

3. S.V. Belousov, Y.V. Khanin, V.V. Zhadko, In the collection: IOP Conference Series: Materials Science and Engineering. Ser. "International Conference on Modern Trends in Manufacturing Technolo-gies and Equipment, ICMTMTE 2020 - Machine Science, Mechanization, Auotomatization and Robotics", Methods and means of concentrated fertilizers application, p. 052050, (2020).

4. A.Ya. Ksenz, S.I. Kambulov, Scientific life, Prospects for improving technology and equipment for applying liquid fertilizers, No. 5, S. 4-11, (2015).

5. S.V. Belousov, S.A. Pomelyayko, V.V. Novikov, In the collection: MATEC Web of Conferences. 2018 International Conference on Modern Trends in Manufacturing Technologies and Equipment, ICMTMTE 2018, Design of the universal agricultural working body and study of its parameters, p. 05006, (2018).

6. I.B. Borisenko, M.V. Meznikova, E.I. Ulybina, Bulletin of the Nizhnevolzhsky agrouniversity complex: science and higher professional education, Scientific aspects of technical modernization of sprayers for chemical protection of sunflower, No. 4 (60), S. 340 - 349, (2020).

7. Borisenko, IB Resource-saving method of chemical treatment of tilled crops / IB Borisenko, AS Ovchinnikov, MV Meznikova, SD Fomin, VS Bocharnikov, AF Rogachev and EI Ulybina // Conference on Innovations in Agricultural and Rural development IOP Conf ... Series: Earth and Environmental Science 341 (2019) 012092 IOP Publishing doi: 10.1088 / 1755-1315 / 341/1/012092.

8. V.I. Pakhomov, V.B. Rykov, S.I. Kambulov, Grain farming in Russia, The results of a comparative assessment of mechanized technologies for the cultivation of grain crops, No. 1. S. 58-62, (2016). 
9. Borisenko, I. B. New technical solution for resource-saving tasks in chemical plant protection / I. B. Borisenko, M. V. Meznikova, O. G. Chamurliev and E. I. Ulybina // E3S Web of Conferences Vol. 285, 01006 (2021) International Conference on Advances in Agro-business and Biotechnology Research (ABR 2021) https://doi.org/10.1051/e3sconf/202128501006

10. Rykov VB Technologies for the introduction of organic, mineral, microelement fertilizers to increase the yield and quality of field crops in conditions of insufficient moisture Pakhomov V.I., Rykov V.B., Kambulov S.I., Vyalkov V.I., Shevchenko N. V., Ksenz A.Ya., Mazhara V.M. Russian Academy of Agricultural Sciences; State Scientific Institution North Caucasian Scientific Research Institute of Mechanization and Electrification of Agriculture of the Russian Academy of Agricultural Sciences (GNU SKNIIMESKH Rosselkhozakademii). Zernograd, 2013. 